\title{
DETERMINANTES PROSÓDICOS EM MUDANÇA SINTÁTICA
}

\author{
Mary Aizawa KATO (D) $\boldsymbol{\Delta}$ \\ Universidade Estadual de Campinas (UNICAMP) \\ Maria Eugenia Lammoglia DUARTE (D) \\ Universidade Federal do Rio de Janeiro (UFRJ)
}

ช

OPEN ACCESS

EDITORES

- Miguel Oliveira, Jr. (UFAL)

- René Almeida (UFS)

AVALIADORES

- Maria Foltran (UFPR)

- Sonia Cyrino (UNICAMP)

SOBRE AS AUTORAS

- Mary Aizawa Kato Conceptualização, Escrita -

Rascunho Original e Escrita - Análise e Edição.

- Maria Eugenia Lammoglia Duarte Escrita - Rascunho Original e Escrita - Análise e Edição.

DATAS

- Recebido: 15/01/2021

- Aceito: 26/02/2021

- Publicado: 15/05/2021

\section{COMO CITAR}

KATO, M.A.; DUARTE, M.E.L. (2021) Determinantes prosódicos em mudança sintática. Cadernos de Linguística, v. 2, n. 1, e350.
RESUMO

O presente trabalho relata uma trajetória de estudos das presentes autoras sobre a mudança no Português Brasileiro (PB), no que diz respeito ao Parâmetro do Sujeito Nulo. Na fase em que esse Parâmetro incluía a inversão livre como uma de suas propriedades, verificou-se que a inversão românica, ou inversão do predicado no PB, era uma regra prosódica, aparentemente independente da perda parcial do sujeito nulo. Verificou-se que, embora a inversão tenha passado a ser restrita no PB, um elemento dêitico ou locativo pré-verbal favorecia a inversão. Além disso, assumindo o sujeito nulo referencial como resultante de elipse do pronome, verificou-se que o apagamento era favorecido quando o verbo era precedido de algum elemento leve. A partir de resultados de diversas pesquisas sobre a fala e a escrita brasileiras, além de dados recolhidos de forma não sistemática, propomos aqui, então, que a ocorrência parcial do sujeito nulo no PB pode ter a ver com uma demanda prosódica parcial, de rejeição a um padrão prosódico sentencial V1, demanda essa não existente no século XIX. Nossa proposta é que, na interface com PF, as línguas têm filtros em relação ao seu ritmo. Para dar conta da preferência de certas formas nesse estágio da mudança, em curso no PB, uma condição do tipo "Evite V1" está sendo proposta. O trabalho não entra, porém, nos aspectos técnicos e formais da prosódia, deixando esta parte para um futuro trabalho*. 


\section{ABSTRACT}

This paper reports a trajectory of studies carried out by the authors about a change in Brazilian Portuguese (PB) related to the Null Subject Parameter. When free inversion was included among the properties associated with this Parameter, our research showed that romance inversion, or inversion of the predicate in BP, was a prosodic rule, apparently independent of the loss of null subjects. Although it became more restricted in BP, VS was still possible, particularly when a preverbal deictic or locative element appeared in first position. Assuming that null referential subjects were a consequence of ellipsis of the referential pronoun, we observed that such ellipsis was also favored by the presence of some light element in first position. Using results from several analyses of Brazilian speech and writing, and data collected from spontaneous conversations, we propose, in conclusion, that the partial occurrence of null subjects in BP can be explained in terms of a prosodic demand, which rejects a V1 sentential pattern, non-existent in the 19th century BP. Our proposal is that, in the interface with PF, languages have filters related to their rhythm. In order to account for the preference for certain forms in the present stage of the change in course in BP, a condition such as "Avoid V1" is being proposed here. The paper doesn't, however, enter into the technical and formal aspects of prosody, which will be the object of future work.

\section{PALAVRAS-CHAVE}

Sujeito Nulo; Inversão Livre; Português Brasileiro;

Opcionalidade; Prosódia.

\section{KEYWORDS}

Null Subjects; Brazilian Portuguese; Optionality; Prosody. 


\section{INTRODUÇÃO}

O presente trabalho relata uma trajetória de estudos sobre a mudança no Português Brasileiro (PB), no que diz respeito ao Parâmetro do Sujeito Nulo (PSN), tópico exaustivamente tratado, formal e empiricamente, pelas autoras do presente artigo, além de outros autores brasileiros que mencionaremos oportunamente (Cf. entre outros, Duarte (1995, 2000, 2018, 2019 e.o.); Kato (1999, 2000a, 2002a, 2003 e.o.) Kato \& Tarallo (2003); Kato \& Duarte (2003; 2014; 2017, 2018); Cyrino, Duarte \& Kato (2000); Barbosa, Duarte \& Kato (2005); Duarte \& Kato (2008). De uma perspectiva macro-paramétrica, o projeto caminha para uma visão micro-paramétrica (Cf. Kayne, 1996), com vistas ainda à proposta de ser o PB uma língua de Sujeito Nulo Parcial (SNP) como o finlandês (cf. Holmberg \& Sheehan 2010)1.

No meio dos linguistas romanistas é hoje bem conhecido o fato de que o PB vem perdendo parcialmente as propriedades de uma língua de sujeito nulo desde a virada do século XX, com a inserção de você (em competição com tu) no sistema pronominal do PB, a partir dos anos 1930, seguida da implementação de a gente, em competição com nós, que se intensifica a partir dos anos 1970, como empiricamente demonstrado em Duarte 1993, 2018.

Duas explicações podem ser dadas por esta parcialidade:

a) A mudança encontra-se ainda em progresso e a existência parcial dos sujeitos nulos, ainda atestados em todos os padrões sentenciais, como veremos, e da inversão livre tem a ver com o fato de que as mudanças não estão completas ainda (cf. Cyrino, Duarte \& Kato 2000) 2 .

1 Segundo os autores, línguas de sujeito nulo parcial permitem controle do sujeito de terceira pessoa da principal sobre os sujeitos nulos do complemento de verbos como dizer, pensare perceber, entre outros:

(I) O João1 disse que (ele1)tinha comprado uma casa.

No PB, embora seja este o padrão mais resistente para a ocorrência de sujeitos nulos, ilustrado em (3), outros padrões ainda licenciam nulos, como mostraremos em (5)-(7). A perda do sujeito nulo no padrão com anti ccomando (exemplo 4) com o sujeito da adjunta anteposta licenciando um nulo na principal posposta), uma propriedade crucial das línguas românicas de sujeito nulo, é quase categórica no PB, mostrando-se o contexto mais facilmente vencido no processo de mudança em curso, nos dados da Língua-E (Cf. DUARTE, 2019).

2 Segundo as autoras, o PB vai se tornando gradualmente uma língua de sujeitos expressos e de objetos nulos, processos que parecem ocorrer independentemente, mas seguem uma mesma hierarquia referencial, que contém num ponto mais alto itens de maior referencialidade, com o traço [+humano], como os pronomes de $1^{\mathrm{a}}$ e $2^{\mathrm{a}}$ pessoas; num ponto mais baixo, vemos os pronomes de $3^{a}$ pessoa, em que os traços [+/-específico] interagem; mais abaixo temos as proposições e, finalmente, os itens não argumentais. Como constatam as autoras, a hierarquia proposta é altamente relevante nos casos envolvendo pronominalização. Quanto mais referencial um item, maior a possibilidade de um elemento expresso, o que explica, o avanço mais rápido do sujeito pronominal expresso de $2^{a}$ e $1^{\mathrm{a}}$ pessoas, bem como os indeterminados (arbitrários ou genéricos), que trazem igualmente o traço inerentemente [+humano]. Seguem mais lentamente, apesar de em estágio já avançado, os itens de $3^{a}$ pessoa, 
b) Os aspectos aparentemente parciais da mudança resultam na inclusão do PB entre as hoje denominadas línguas de SNP, de acordo com o qual essas línguas exibem sujeitos nulos referenciais opcionais, além de expletivos nulos ou expressos e também sujeitos nulos de interpretação genérica.

O objetivo final deste trabalho é mostrar que a variação/opcionalidade das propriedades do Sujeito Nulo Referencial (SNR) no PB atual é de ordem prosódica/estilística, sendo definida na interface com a PF.

Veremos inicialmente que a opcionalidade dos sujeitos nulos referenciais tem a ver com fatores estilísticos de dois tipos: a) o primeiro tem a ver com uma gramática conservadora adquirida via instrução, em alternância com a gramática inovadora nuclear da criança, e b) o segundo tem a ver com a preferência do brasileiro no século XX por uma prosódia linear V2.

Em seguida, veremos que a inversão livre, atribuída ao Parâmetro do Sujeito Nulo (PSN), também tem a ver com restrições de peso prosódico, tendo o PB uma preferência pelo padrão linear V2.

\section{A VARIAÇÃO/OPCIONALIDADE NA DIACRONIA}

\subsection{A VARIAÇÃO NO INDIVÍDUO}

Vejamos inicialmente o que dizem dois mestres diacronistas sobre variação e/ou opcionalidade na sintaxe e/ou na morfologia:

\footnotetext{
The spread of a new parameter setting through a speech community is typically manifested by categorically different authors rather than by variation within the usage of individuals, although the data are sometimes not as clear as that idealization would suggest, because a writer often commands more than one form of a language (Lightfoot, 1991, p. 162).

Syntactic heads, we believe, behave like morphological formatives generally in being subject to the well-known "Blocking Effect" (Aronoff 1976), which excludes 'morphological doublets', and more generally, it seems, any coexisting formatives that are not functionally differentiated... This exclusion, however, does not mean, either for morphology or for syntax, that languages never exhibit doublets. Rather it means that doublets are always reflections of unstable competition between mutually exclusive grammatical options (Kroch, 1994, p. 181).
}

\footnotetext{
especialmente quando interagem os traços [-humano/-específico]. No ponto mais baixo da hierarquia estão os expletivos, que se mantêm nulos no PB, embora já em competição com uma serie de estruturas de alçamento (Duarte \& Kato, 2008; Kato \& Duarte, 2017; Duarte 2017, e.o.). O objeto nulo segue direção oposta, a partir dos itens proposicionais ou neutros.
} 
O que fica claro nesses autores é que a opcionalidade morfossintática dentro de uma mesma gramática, de um mesmo indivíduo, não deveria ser possível. A variação pode ser encontrada entre indivíduos numa mesma comunidade, ou dentro de um mesmo indivíduo quando este domina mais de uma gramática em competição.

Aqui, entretanto, defenderemos que variação estilística pode existir no mesmo indivíduo uma vez que esta tem a ver com a Forma Fonética (PF) e não com o componente computacional ${ }^{3}$. Defenderemos que a variação atestada na escrita e na fala do PB tem caráter prosódico e não constitui doublets morfológicos ou sintáticos no sentido de Aronoff (1976) e Kroch (1994).

\subsection{O QUE DIZEM OS DADOS EMPÍRICOS}

A perda do princípio Avoid pronoun (Chomsky, 1981) encontra evidência em autores do século XX em oposição aos do século XIX, como mostra o estudo de Duarte (1993; 2018).

(1) a. $\varnothing_{2 p s}$ terá o cavallo que $\varnothing_{2 p s}$ deseja

b. já ontem $\varnothing_{1 p s}$ comprei-lhe 0 hábito com que $\varnothing_{i \text { ips }}$ andará vestido.

(“O noviço", Martins Pena, 1845, séc. XIX)

(2) a. Se eu ficasse aqui eu ia querer ser a madrinha.

b. Você não entende meu coração porque você 'tá sempre olhando pro céu e procurando chuva.

c. Agora ele não vai mais poder dizer as coisas que ele queria dizer.

(“No coração do Brasil”, Miguel Falabella, 1992, séc. XX)

Contudo, veremos que, ao contrário dos exemplos acima, os dados revelam a forma velha (sujeito nulo) e a nova (o pronome expresso) em variação no indivíduo da mesma época, o que reforça, à primeira vista, a hipótese de uma língua de sujeito nulo opcional e, portanto, da existência de línguas de Sujeito Nulo Parcial, ainda que o caso do PB não se mostre como um sistema estável. Os exemplos em (3) e (4) mostram essa opcionalidade em dados de fala espontânea de amostra recente (Duarte, 2019). Enquanto os sujeitos nulos no padrão ilustrado em (3), com c-comando, já chegam a 41\%, sendo, pois, superados pelo pronome expresso, os nulos em (4), no padrão sem c-comando alcançam 11,5\%, o percentual mais baixo nos cinco padrões considerados na análise de Duarte (2019)4.

(3) a. [Os pais eles]i passam aos filhos o que eles têm, né?

b. [Meu marido]i foi quase preso aí no forte porque $\emptyset_{i}$ foi mergulhar.

3 Para Chomsky \& Lasnik 1977 regras estilísticas se localizam na Forma Fonética (PF) e não no componente computacional.

4 Na amostra do PE, o sujeito nulo é quase categórico nos padrões com e sem c-comando ilustrados em (3) e (4). 
(4) a. Se ele tem medo, alguma coisa ele fez.

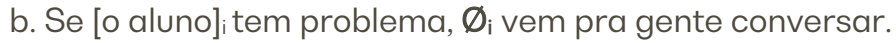

Na análise de Barbosa, Duarte e Kato (2005), os dois padrões com e sem ccomando, não tiveram análise à parte. Na realidade, no PE, o comportamento dos dois padrões é idêntico, com alto favorecimento do sujeito nulo (94\% e 93\%, respectivamente). Portanto, no $P E$, a adjacência e função idêntica se sobrepõem ao padrão sentencial. Os três outros padrões, propostos na análise de Barbosa, Duarte e Kato - antecedente em período adjacente, com a mesma função (5), antecedente com função diferente da de sujeito (6) e antecedente distante (7), continuam a exibir opcionalidade no PB, embora com índices inferiores ao padrão com c-comando (38\%, $21 \%$ e $14,5 \%$ de sujeitos nulos respectivamente (DUARTE, 2019).

(5) a. [César Maia] era mais tranquilo. Ele $e_{i}$ investia mais.

b. Ele $e_{i}$ era bem mais novinho. $\emptyset_{i}$ Trouxe o dinheiro no bolso.

(6) a. Eu não posso ter sentado do lado de [um cara bonitinho] $]_{i}$ tal sem perceber que ele era superperigoso.

b. Porque eu preciso ter a minha linguagem formal com [meu cliente]. De repente, $\emptyset_{\mathrm{i}}$ é um cara que tem uma condição, ou um cara que usa daquele jeito.

(7) a. [O meu filho] tava chegando em casa - que nós trabalhamos com festa, como eu te falei, né - e ele tinha ido comprar bolas. Aí, não tinha as bolas que nós queríamos. Ele $e_{i}$ trouxe o dinheiro de volta.

b. $\emptyset_{\mathrm{i}}$ casaram e foram morar em Ipanema, num apartamento na Joana Angélica - uma gracinha! 0 prédio ainda existe até hoje. Depois, quando eu nasci, mamãe tava grávida.

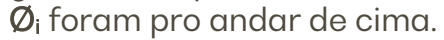

\subsection{A VARIAÇÃO/OPCIONALIDADE DO BRASILEIRO NA ESCOLARIZAÇÃO}

Assumimos que a gramática nuclear (core grammar), que se adquire via assentamento de parâmetros, não tem doublets. Gramáticas nucleares contêm sempre a variante inovadora (Lightfoot, 1999).

Simões (2000) dá evidências dessa afirmação ao constatar que, nas crianças em fase de aquisição do PB$^{5}$, no que diz respeito ao Parâmetro do Sujeito Nulo (PSN), o sujeito referencial é sempre um pronome, enquanto o sujeito nulo é sempre um expletivo.

5 A autora é do Rio Grande do Sul, onde se preserva o pronome 'tu', embora este pronome tenha perdido a flexão de concordância correspondente. 
(8) a. Eu tô botando

b. Não quer, tu não quer $\varnothing$ ?

c. Ela anda a cavalo, anda de moto, ela anda.

(André, 2;4) (exs. de Simões, 2000)

(9) a. $\varnothing_{\text {expl }}$ Tem dois aviões.

b. Ø $\varnothing_{\text {expl }}$ É esse que cabe.

(André, 2;4) (exs de Simões, 2000)

Mas, como se verá no estudo de Magalhães (2000), as Gramáticas Nucleares são adquiridas antes da idade do letramento. A Tabela 1, a seguir, com resultados do processo de letramento, mostra que, no $1^{\circ}$ grau, o escolar apresenta quase $100 \%$ de pronomes expressos, com $2 \%$ de nulos referenciais, o que atesta que estes não estavam presentes na sua gramática nuclear. No final do Ensino Fundamental 1, a criança revela 22\% de nulos e chega ao final do Fundamental 2, com uma competição entre pronomes nulos e expressos na sua escrita.

\begin{tabular}{|l|l|l|l|}
\hline Sujeitos referenciais & $1^{\circ}$ grau & $3^{\circ}$ e $4^{\circ}$ graus & $7^{\circ}$ e $8^{\circ}$ graus \\
\hline Sujeitos Pronominais & $97,89 \%$ & $78,0 \%$ & 50,38 \\
\hline Sujeitos Nulos & $2,11 \%$ & $22,0 \%$ & $49,62 \%$ \\
\hline
\end{tabular}

Tabela 1. Sujeitos referenciais durante o processo de letramento (apud Magalhães, 2000).

É então que se observam os casos de variação, ou doublets, confirmando o papel da escolarização, como mostram os exemplos de Magalhães (2000) em (10).

(10) a. $\varnothing_{1 p s}$ vou pedir uma ordem ao médico porque eu 1 não agüento ver você sofrer mais.

( $7^{\mathrm{a}}$ série)

b. Eu $u_{1}$ estou de castigo, porque $\varnothing_{1 p s}$ briguei com minha irmã e $\varnothing_{1 p s}$ não vou poder jogar futebol hoje. ( $7^{\text {a }}$ série)

Note-se, porém, que no exemplo (10a) a oração principal vem com o sujeito nulo, ccomandando o pronome expresso na subordinada, enquanto o exemplo (10b) apresenta o contrário, o que mostra que a variação não envolve c-comando. O que esses doublets evidenciam são reflexos da competição instável entre gramáticas. Segundo Kato (1994), a variação/opcionalidade que vemos nos estudantes e no adulto letrado constitui um fenômeno de code-switching (alternância de códigos) do falante bilíngue, e o efeito é estilístico6

6 Para Chomsky (1988) a língua-I do adulto pode conter uma periferia estendida com formas antigas, ou até mesmo uma segunda gramática, o que acontece com a língua-I de filhos de imigrantes. Ver ainda Kato (2013). 
Quanto à língua-E do adulto letrado, podemos considerar que o índice de sujeitos nulos seria similar ao do escolar da $7^{\mathrm{a}}$ e $8^{\mathrm{a}}$ séries. A análise de Duarte (2007), que compara os resultados para sujeitos nulos de $3^{a}$ pessoa na fala espontânea de PE e PB (1995) com a escrita jornalística (editoriais, reportagens e crônicas) das mesmas variedades, não deixa dúvidas de que o PE é um sistema estável de sujeitos nulos, enquanto o PB revela uma diferença pouco significativa entre fala e escrita, embora os índices atestados para a escrita standard se igualem aos encontrados por Magalhães em crianças no final do curso Fundamental. O PE mantém um índice alto na fala e faz uso quase categórico do sujeito nulo na escrita do adulto letrado.

\begin{tabular}{|l|l|l|l|}
\hline FALA & ESCRITA \\
\hline PE (1995) & PB (1995) & PE (2007) & PB (2007) \\
\hline $303 / 417$ & $209 / 546$ & $227 / 244$ & $119 / 241$ \\
$73 \%$ & $38 \%$ & $\mathbf{9 3 \%}$ & $49 \%$ \\
\hline
\end{tabular}

Tabela 2. Sujeitos nulos de $3^{\text {a }}$ pessoa na fala e na escrita de adultos portugueses e brasileiros (Adaptada de Duarte, 1995, 2007)

Nos exemplos que seguem, retirados de Duarte (2007), apresentamos exemplos de instabilidade na escrita de jornais brasileiros. Note-se, em primeiro lugar, a opcionalidade nos contextos com c-comando (11) e com antecedentes em outra função (12).

(11) a. Durante a solenidade, César Maia anunciou um pacote de obras que $\varnothing_{i}$ autorizou para a Barra e o Recreio, já pensando na realização dos Jogos Pan-Americanos.

b. Ele $e_{i}$ explicou que à tarde ele vai se dedicar a fazer uma avaliação de todas as alternativas de perguntas

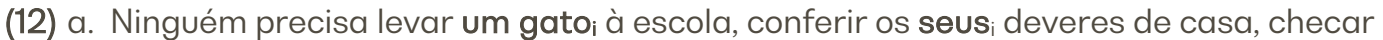
se $\varnothing_{i}$ escovou os dentes antes de ir para a cama (...)

b. A França se prepara para o ataque ao inimigoi. Sabe que ele $e_{i}$ se aproxima, mas não sabe exatamente quando $\varnothing_{\text {i }}$ aparecerá.

Note-se ainda que o paradigma de pronomes pessoais fracos para referentes não humanos, desenvolvido a partir da perda do caráter pronominal da flexão (Kato 1999) e já avançado na fala, se encontra plenamente implementado na escrita:

(13) a. [O governo] não considera nem o fato de que os possíveis desvios, injustiças e exageros de que [ele] tanto se queixa são criticados na própria imprensa (...). b. Ainda não se falava [na incrível sorte que acompanha Felipão]. [Ela]i só ficaria evidente para os portugueses no jogo contra a Inglaterra.

Em suma, a análise de Duarte (2019), com base em amostras gravadas em Lisboa e Rio de Janeiro, disponíveis em www.comparaport.letras.ufri.br), confirma o progresso da mudança no PB (24\% de sujeitos nulos de $3^{\text {a }}$ pessoa) e a estabilidade do PE (67\%). Ao mesmo 
tempo, os resultados mostram que o sujeito nulo no PE, em estruturas com e sem ccomando é quase categórico com referentes com o traço [-humano] (em torno de 98,25\%), enquanto o PB já exibe $50 \%$ de sujeitos nulos com esse traço. Estamos, pois, a meio caminho do não-apagamento de pronomes pessoais [-humanos], um traço que as línguas de sujeito nulo "consistente" do grupo românico (Roberts \& Holmberg, 2010) não exibem. Em resumo, enquanto o PE se mantém como um sistema estável de sujeitos nulos (apesar de exibir raros pronomes com o traço [-humano], o PB caminha em direção aos sujeitos pronominais expressos em todos os contextos.

\section{A PERDA DA INVERSÃO LIVRE NO PB}

\subsection{O PAPEL DA PROSÓDIA NA EXISTÊNCIA DA INVERSÃO}

Conscientes da mudança no PB, no que toca à perda parcial do sujeito nulo, Kato e Tarallo (1989, 2003), levantam a hipótese da perda da inversão "livre" no PB, como parte do mesmo macro-parâmetro. Mas os autores verificam que a inversão livre é ainda possível com verbos inacusativos?:

(14)a. Chegou o trem.

b. ?Dormiu o bebê.

c. ??Assinou a carta o chefe do departamento.

d. ???Enviou a carta a todos o presidente da empresa.

Kato (2000a), em pesquisa sobre inversão livre nas línguas românicas, identifica o motivo que está por trás da perda da inversão no PB. Estudando as ocorrências da inversão no espanhol e no italiano, a autora verifica um fato empírico interessante. Bentivoglio \& D’íntrono (1978), para o espanhol, e Benincá \& Salvi (1988), para o italiano, atestam que a inversão livre é mais bem aceita quando os complementos são clíticos e concluem que a inversão livre é propriedade de línguas que têm clíticos.

(15) a. Lo instaló Esteban.

b. Quería hacerlo Juan.

(16) a. L'há mangiata la mamma.

b.?Há mangiato la torta la mamma. 
Kato conclui que, no PB, a restrição vista para o espanhol e o italiano foi agravada pela perda de parte do paradigma dos clíticos ${ }^{8}$, perda essa que fez o lado do complemento mais pesado.

(17) a. Comprou-lhe uma joia o Pedro.

(PE e PB Século XIX)

b. Comprou-lha o Pedro.

(PE e PB Século XIX)

c. ${ }^{*}$ Comprou pra ela uma joia o Pedro.

(PB Século XX)

d. ${ }^{*}$ Comprou uma joia pra ela o Pedro.

(PB século $X X)$

Zubizarreta (1998) vem ao encontro do achado empírico de Kato, propondo que a inversão livre resulta de uma regra geral de movimento condicionada pela prosódia, que ela denomina P-movement 9 . A existência de clíticos e sua natureza leve, explicam por que a inversão livre é encontrada em línguas românicas com um sistema robusto de clíticos, enquanto no PB a perda dos clíticos acabou por reduzir a inversão do predicado apenas a verbos inacusatios. Sendo, pois, a impossibilidade de inversão livre relacionada à ausência de clíticos, particularmente os de $3^{a}$ pessoa, é possível cogitar que a inversão livre seria um fenômeno independente do licenciamento de sujeitos nulos.

\subsection{ELEMENTOS LEVES PRÉ-VERBAIS NA INVERSÃO LIVRE}

Kato (2002a) e Kato \& Duarte (2003), em um projeto sobre o PB falado, concluíram que esta variedade do português rejeita estruturas com verbo em posição inicial (V-inicial) na inversão livre, com verbos transitivos e intransitivos, mas que a adição de um elemento leve em posição inicial tornava as sentenças possíveis. Esses elementos podem ser adjuntos, complementos ou até mesmo elementos discursivos. As autoras associaram essa restrição ao novo ritmo prosódico da língua, uma consequência do reassentamento do PSN.

(18) a. Ali dorme o meu gato.

b. E se impôs essa atitude sua.

c. Depois do diretor, assinou a carta o chefe do departamento.

Em 2006, Pilati propôs que a inversão livre se obtém mais facilmente quando um elemento dêitico ou locativo satisfaz o EPP (18), com a ocupação da posição $V$-inicial ${ }^{10}$. Em (16c), a autora mostra que o locativo pode controlar o sujeito da encaixada:

8 Sobre perda de clíticos no PB ver Duarte 1986; Cyrino 1993, 2019; Nunes 1993, 2019; Pagotto 1993i.a.

9 Ver resenha dessa obra de Zubizarreta em Kato (2000c).

10 Muitos exemplos de Pilati são de narração de jogo de futebol - uma tradição discursiva que vai cada vez menos mostrando VS. 
(19) a. . Dormem aqui as crianças.

b. Aqui dormem as crianças

c. Aqui dormem as crianças porque $\emptyset_{\mathrm{i}}$ é mais quentinho.

Mais recentemente, Buthers \& Bonfim Duarte (2012) propõem que, à medida que o PB se torna uma língua de sujeito nulo parcial11 - com pronomes referenciais expressos, mas com expletivos nulos - constituintes locativos podem se gramaticalizar como expletivos, tal como o there do inglês. Com isso, o padrão XP V (YP) também a aumenta.

(20)a. Lá vai o time de futebol.

b. Ali fica a mesa.

c. Na praia temmuita gente.

d. A praia tem muita gente.

\subsection{A FUNÇÃO DA ORDEM VS/SV COM INACUSATIVOS}

Nas línguas românicas de sujeito nulo as ordens VS/SV coexistem, em geral, para codificar os juízos tético (apresentativo) /categórico (predicacional), independentemente do tipo de verbo $^{12}$. Com os verbos inacusativos, o PB mantém ainda essa distinção, mas, para muitos falantes, o inacusativo já está seguindo a tendência dos demais verbos, a de codificar juízos téticos com a ordem SV13 como em (21b).

(21) a. Chegou uns ovos estragados.

(tético)

b. Uns ovos que você encomendou chegaram estragados. (tético)
c. A Maria chegou.
(tético ou categórico)
d. A Maria, ela chegou.
(categórico)

A falta de concordância com o argumento interno dos inacusativos na ordem VS, como ilustrado em (21a), levou Kato (2002b) a propor que essa construção teria sido resultado de reanálise dos inacusativos como um verbo existencial com um sujeito expletivo nulo do tipo dêitico como aqui, aí, agora. Daí a não concordância entre verbo e argumento interno.

11 Uma classificação, que, como vimos, não se conforma para o PB com o rótulo que tem sido usado para línguas que admitem um sujeito nulo em condições muito restritas

12 Cf. a distinção entre tético vs categórico em Kuroda (1972). Ver também Kato \& Martins (2016) e Kato \& Duarte (2018b).

13 Cf. Britto (2000) para quem a perda da ordem VS levou SV a assumir o caráter tético e o deslocamento 'esquerda a função categórica.

(I) O bebê sorriu.(tético) (ii) $\mathrm{O}$ bebê, ele sorriu. (categórico) 
A ordem SV dos inacusativos apresenta, por outro lado, uma novidade no PB: alçamento de um genitivo ou dativo para atender ao EPP14. A construção categórica genitiva como (22b), com a perda do genitivo de $3^{a}$ pessoa, passa a exibir, em seu lugar, uma construção que se denominou tópico-sujeito. Por outro lado, com a perda do clítico dativo Ihe/lhes de terceira pessoa, perdemos o CLLD (Deslocamento Clítico à Esquerda), como em (23b), e passamos a ter uma construção de tópico-sujeito.

(22) a Quebrou os ponteiros dos relógios.

(tético) PB

b. Os relógios tiveram seus ponteiros quebrados. (categórico) PE

c. Os relógios quebraram o(s) ponteiro(s). $\quad$ (categórico) BP Tópico-sujeito
a. Faltou sorte aos meus times.
(tético)
BP PE
b. Aos meus times, faltou-lhes sorte.
(categórico) *BP PE CLLD
c. Os meus times faltaram sorte.
(categórico) BP *PE Tópico-sujeito

Para Duarte e Kato (2008) essas construções apareceram em função da perda do sujeito nulo referencial no PB e sua passagem de uma língua de proeminência do sujeito para uma língua de prominência de tópico, visão partilhada por outros linguistas brasileiros ${ }^{15}$. Para Kato \& Ordoñez (2019), porém, o aparecimento da construção de tópicossujeitos se deve não só ao empobrecimento do paradigma de concordância, mas também às perdas ocorridas no sistema de clíticos dativos do PB e da perda do possessivo de terceira pessoa, que afetou, como consequência, a construção de CLLD (Clitic Left Dislocation) e as construções genitivas com seu/seus/sua/suas para referência à terceira pessoa em construções categóricas do $\mathrm{PB}$, o que não ocorre no $\mathrm{PE}$.

Sentenças locativas constituem outra classe que vem sofrendo mudança semelhante, com alçamento do locativo para formar um padrão de tópico-sujeito. Um jornalista anunciando o tempo pode usar tanto (24a) como (24b) ao começar um noticiário. Mas, se ele acrescentar "Rio" à mesma notícia, deverá usar a variante (24c.)

(24) a. Chove em São Paulo.

b. São Paulo chove.

c. Chove em São Paulo; no Rio faz sol. (tético)

(tético ou categórico).

(tético; categórico)

14 Fenômeno introduzido por Pontes $(1981,1987)$ e estudado por muitos linguistas brasileiros, entre eles Kato 1989; Galves 1998; Modesto 2008; Negrão 1999, Duarte \& Kato 2008, Kato \& Duarte 2008; Kato \& Duarte 2017 ; Kato \& Ordoñez 2019 e. o

15 Cf. entre outros os autores citados na nota 11. 
Há, entretanto, uma tendência hoje à preferência por SV para expressar o juízo tético, o que possibilita evitar o padrão linear $\mathrm{V}^{116}$. Nos dados recolhidos de maneira não sistemática, o exemplo que ilustra (24c) foi ouvido no início do noticiário sobre o tempo em São Paulo tal como mostramos em (25d).

(25) d. São Paulo chove; o Rio faz sol.

\section{DESENCADEADOR MORFOLÓGICO E CONSEQUÊNCIA PROSÓDICA}

Até recentemente, assumia-se que a perda parcial dos sujeitos nulos referenciais tinha a ver com a perda da riqueza morfológica do nosso paradigma de flexões de pessoa (DUARTE 1995, e.o.) e a sua substituição por pronomes fracos livres (CARDINALETTI; STARKE, 1999; KATO 1999).

Sem ignorar a perda da riqueza morfológica em virtude da mudança no paradigma pronominal e a proeminência de tópico no PB, aqui propomos que, no nível da Forma Fonética, passamos a ter uma mudança paralela na prosódia sentencial. Da possibilidade de V-inicial das línguas prototípicas de sujeito nulo, passamos a ter preferência pelo padrão linear V2. Também com a inversão livre, há uma rejeição inicial dessa construção V1, sanada parcialmente com a presença de elementos dêiticos iniciais, resultando em construções lineares V2.

\subsection{SUJEITOS NULOS SÃO SUJEITOS ELÍPTICOS}

Ao invés da clássica análise de sujeito nulo como pro, adotamos o conceito de sujeito nulo como elipse de pronome (cf. PERLMUTTER, 1971; HOLMBERG, 2005; ROBERTS, 2010). Evidência para essa concepção pode ser vista na série de exemplos abaixo.

Embora V2 tenha se tornado o padrão sentencial preferencialmente com sujeito expresso, o apagamento do sujeito pode ocorrer quando ocorrem elementos leves preverbais como a negação, clíticos, locativos em primeira posição (DUARTE, 1995; KATO; DUARTE, 2018a), que preservam o padrão V2.

16 Para Kato \& Ordoñez (2019), o padrão SV pode ser já uma construção antiga desde o desaparecimento do clítico hi (Chove hi em São Paulo) no período clássico (cf. Castilho 2007). 
(26) a. (Eu) Já trabalhava naquela época.

b. (Cê) Nunca ouviu falar nele?

c. (Ele) Não aguentou o tranco.

d. (Eu) Me tornei independente.

Veja ainda o seguinte contraste:

(27) a. \%* como cenouras cruas.

b. Não como cenouras cruas.

c. Só como cenouras cruas.

d. Eu como cenouras cruas.

Até mesmo a criança citada acima por Simões, com três anos de idade, que distribui os nulos apenas para expletivos (28), apresenta uns poucos exemplos de nulos referenciais quando o verbo é precedido de algum elemento:

(28)a. Não tô conseguindo. (Andrés, 3,0)

b. Também são assim. (Andrés, 3,0)

\section{CONCLUSÃO: DE “EVITE PRONOME” (CHOMSKY 1982) PARA “EVITE V1"}

Concluindo, podemos afirmar que uma regra estilística prosódica afeta tanto a inversão livre quanto a sentença com sujeito nulo no PB:

(29) a. Lá vem a Maria. (V2)

b. ${ }^{*}$ Vem lá a Maria. (V1)

(30) a. Você é americano? (V2)

b. 'É americano?

Logo, embora o sujeito nulo e a inversão sejam independentes quanto ao que motiva a mudança, a perda da riqueza morfológica de pessoa, no primeiro caso, e a perda parcial dos clíticos, no segundo, os dados aqui apresentados permitem concluir que o resultado da mudança é uniformemente atingido pelo ritmo prosódico, que favorece um padrão linear $\mathrm{V} 2$.

Nossa proposta é, portanto, que, na interface com PF (Forma Fonológica), as línguas têm filtros em relação ao seu ritmo. Para dar conta da preferência por certas formas nesse estágio da mudança em curso no PB, essa proposta pode ser traduzida numa condição do tipo "Avoid V1".

A sequência V2 que resulta dessa condição, entretanto, nada tem a ver com o que acontece com a ordem V2 das línguas germânicas, cuja motivação é estrutural, com um XP 
que se move para Spec, C a fim de satisfazer o EPP. Esse contraste mostra que, no caso do PB, o elemento preverbal pode ser um X (um núcleo) ou um XP (uma projeção máxima). Podemos conjeturar que o padrão rítmico entra como um tipo de Parâmetro, tal qual a morfologia. No estágio atual da mudança em curso, a criança provavelmente seria sensível à prosódia antes da morfologia.

\section{AGRADECIMENTOS}

Agradecemos a um dos pareceristas que nos indica dois itens bibliográficos que podem ser úteis para esse futuro trabalho (*), a saber, Mara Frascarelli e Tania Stortini (2019); levaremos também em conta o trabalho de Adams (1988), que tratou da mudança na passagem do francês antigo para o médio, para língua sem sujeitos nulos, levando em conta o efeito da prosódia.

\section{REFERÊNCIAS}

ADAMS, Marianne. Parametric Change: Empty Subjects In Old French. Parametric change: empty subjects in Old French. In: BIRDSONG. D; MONTREUIL, J-P. (eds.) Advance in Romance Linguistics. Dordrecht: Foris. 1988.

ARONOFF, Mark. Word formation in Generative Grammar. Cambridge, MA: the MIT Press, 1976.

BARBOSA, Pilar.; DUARTE, M. Eugênia L. \& KATO, Mary A. Null subjects in European and Brazilian Portuguese. Journal of Portuguese Linguistics, vol. 4 (2): Studies in the Comparative Syntax of European and Brazilian Portuguese, 11-52, 2005. KATO, Mary A.; PERES, João A. (orgs).

BENINCÁ, Paola; SALVI, Gianni. L'ordine normale degli elementi nella frase símplice. In L. RENZI. (ed.) Grande Grammática Italiana di Conzultazione. Vol I. Bologna: II Mulino.119-29, 1988.

BENTIVOGLIO Paola; D'INTRONO, E. Orden de palabras y posición del sujeto en español de Caracas: un estudio sociolinguistico. Trabalho apresentado no V Congresso Internacional da ALFAL. Caracas, Venezuela, 1978.

BIBERAUER, Teresa; HOLMBERG, Anders; ROBERTS, lan; SHEEHAN, Michelle. (eds.) Parametric Variation: Null subjects in Minimalist theory. Cambridge: Cambridge University Press, 2010.

BRITTO, Helena. Syntactic codification of categorical and thetic judgments in Brazilian Portuguese. In: KATO, Mary A; NEGRÃO, Esmeralda V. (orgs.), 2000: 195-222

BUTHERS, Carla M. \& BONFIM DUARTE, Fábio. Português Brasileiro: uma língua de sujeito nulo ou de sujeito obrigatório? Diacrítica, 26:1. 65-89. 2012.

CASTILHO, Celia. Processos de redobramento na diacronia do Português. UNICAMP, Tese de Doutorado em Linguística, Campinas. 2007.

CARDINALETTI, Anna; STARKE, Michal. The typology of structural deficiency: a case study of three classes of pronouns. In: Van RIEMSDIJK, H (ed.) Clitics in the Languages of Europe. Berlin: Mouton de Gruyter, 1999: 145-235.

CHOMSKY, Noam Lectures on Government and Binding, Dordrecht: Foris, 1981. 
Press, 1982

Some Concepts and Consequences of the Theory of Government and Binding. Cambridge, Mass: The MIT

Language and problems of knowledge: the Managua lectures. Cambridge, MA: MIT Press, 1988.

LASNIK, Howard. On filters and control. Linguistic Inquiry 8: 425-504, 1977.

CYRINO, Sonia. Observações sobre a mudança diacrônica no português do Brasil: objeto nulo e clíticos. In: ROBERTS, Ian; KATO, Mary A. (eds.) 1993:163-184. $3^{\text {a }}$ ed. São Paulo: Editora Contexto, 2018: 129-142.

O objeto nulo do português brasileiro: sincronia e diacronia. In: GALVES, Charlotte; KATO, Mary A.; ROBERTS, lan (orgs). Campinas: Ed. da UNICAMP. 2019: 173-200.

DUARTE, M. Eugênia L; KATO, Mary A. Visible subjects and invisible clitics in Brazilian Portuguese. In: KATO, Mary A.; NEGRÃO, Esmeralda V. (eds.), 2000: 55-74.

DUARTE, M. Eugênia L. Variação e Sintaxe: clítico acusativo, pronome lexical e categoria vazia no português do Brasil. Dissertação de Mestrado, PUC-SP, 1986.

A perda da ordem V(erbo) S(sujeito) em interrogativas-Qu no português do Brasil. Revista D.E.L.T.A., v. 8 (número especial), 37-52, 1992.

Do pronome nulo ao pronome pleno: a trajetória do sujeito no português do Brasil. In: ROBERTS, lan; KATO, Mary A. (eds.) 1993: 107-128. $3^{\text {a }}$ ed. São Paulo: Editora Contexto, 2018: 107-128 1995.

A perda do princípio "Evite Pronome" no Português brasileiro. Tese de Doutorado, UNICAMP, Campinas,

The loss of the Avoid Pronoun Principle in Brazilian Portuguese. In: KATO, Mary A.; NEGRÃO, Esmeralda V. (eds.) Brazilian Portuguese and the Null Subject Parameter. Frankfurt: Vervuert/lberoAmericana, 2000, 17-36.

Sujeitos de referência definida e arbitrária: aspectos conservadores e inovadores na escrita padrão. Revista Lingüística - Revista do Programa de Pós-Graduação em Linguística, 3 (1), UFRJ, 2007, 89-15.

. Analyzing a parametric change in Brazilian Portuguese: A sociolinguistic investigation. In: BARBOSA, Pilar; PAIVA M. da Conceição; RODRIGUES, Celeste (eds.) Studies on Variation in Portuguese, v. 14 Amsterdam/Philadelphia: John Benjamins, 2017: 233-256.

FRASCARELLI, Mara; STORTINI, Tania. Focus constructions, verb types and the SV/SVS order in Italian: an acquisitional study from a syntax-prosody perspective. Lingua: International review of general linguistics, $v$. 227, 2019.

O sujeito nulo referencial no Português Brasileiro e no Português Europeu. In: GALVES, Charlotte; KATO, Mary A.; ROBERTS, lan (orgs). Português Brasileiro: uma segunda viagem diacrônica. Campinas: Editora da UNICAMP, 2019: 93-126.

KATO, Mary A. Mudança paramétrica e orientação para o discurso. Comunicação apresentada no XXIV Encontro Nacional da Associação Portuguesa de Linguística. Braga, Portugal, 2008.

GALVES, Charlotte. Tópicos, sujeitos, pronomes e concordância no português brasileiro. Cadernos de Estudos Linguísticos, 34, 7-21, 1998.

KATO, Mary A.; ROBERTS, lan. (orgs.) Português Brasileiro: uma segunda viagem diacrônica, Campinas: Ed. da UNICAMP, 2019

HOLMBERG, Anders. Is there a little pro? Evidence from Finnish. Linguistic Inquiry, 35, 533-64, 2005.

; SHEEHAN, Michelle. Control into finite clauses in partial null subject languages. In: BIBERAUER, Teresa HOLMBERG, Anders; ROBERTS, lan; SHEEHAN, Michelle (eds.) 2010: 125-152.

KATO, Mary A. Sujeito e tópico: duas categorias em sintaxe? Caderno de Estudos Linguísticos,17:109-132, 1989

Metalinguistic reflections on code-switching. In: BARBARA, Leila; SCOTT, Mike (eds.) Reflections on Language Learning. Clevedon: Multilingual Matters, 1994, 122-137. 
Strong pronouns, weak pronominals and the null subject parameter. Probus, 11 (1): 1-37, 1999.

A restrição de monoargumentalidade da ordem VS no PB. Forum Linguístico, (2)1: 97-127, 2000a.

The partial pro-drop nature and the restricted VS order in Brazilian Portuguese. In: KATO, Mary A.;

NEGRÃO, Esmeralda V. (eds.) 223-258, 2000b.

$174,2000 c$

(2000c) Resenha de Prosody, Focus and Word Order, Zubizarreta, M.L. (1998). Revista D.E.L.T.A.16,1: 155-

La gramática del portugués hablado: reflexiones sobre el uso de la lengua. In: CURCO, C; COLIN, M, GRULT, N.; HERRERA, L. (eds.) Contribuciones a la linguística aplicada en America Latina. México: CELE-UNAM, 2002a: 363-378

The reanalysis of unaccusative constructions as existentials in Brazilian Portuguese. Revista do GEL. Assis, número especial, p. 157-186, 2002 b.

A gramática nuclear e a língua-I do brasileiro. In: M. A. MARTINS (org.) Gramática e Ensino. Natal: EDUFRN, 2013: 149-166.

TARALLO, Fernando. Restrictive VS syntax in Brazilian Portuguese: its correlation with invisible clitics and visible subjects, Comunicação apresentada no congresso Georgetown RoundTable in Languages and Linguistics, 1989.

The loss of VS syntax in Brazilian Portuguese In: B. SCHLIEBE-LANGE, I. KOCH \& K. JUNGBLUTH (eds.) Dialogue between Schools: sociolinguistics, conversational analysis and generative theory in Brazil. Münster: Nodus Publicationen, Klaus D. Ditz, 2003, 101-129.

; Negrão, Esmeralda (eds.) Brazilian Portuguese and the Null Subject Parameter. Frankfurt am Main: Vervuert/lberoAmericana. 2000.

DUARTE, M. Eugênia L. Semantic and phonological constraints on the distribution of null subjects in Brazilian Portuguese. Comunicação apresentada no Congresso NWAV32, University of Pennsylvania, Philadelphia, 2003.

Restrições na distribuição de sujeitos nulos no Português Brasileiro. Revista VEREDAS, 18 (1), 1-22, 2014.

O sujeito no Português Brasileiro e sua tipologia. In: PILATI, Eloisa, SALLES, Heloisa; NAVES, Rosana (orgs.) Novos olhares para a gramática do Português Brasileiro. Campinas: Editora Pontes, 2017: 13-42.

Pre-verbal position in BP: a re-interpretation of the "Avoid Pronoun Principle". DIADORIM, Revista do Programa de Pós-Graduação em Letras Vernáculas, 20, Número Especial, 620-626, 2018a.

. A codificação dos juízos téticos e categóricos no português brasileiro. In: MEDEIROS, Alessando B. de; NEVINS, Andrew (orgs.). O Apelo da Árvores. Campinas: Editora Pontes, 2018b: 15-44.

MARTINS, Ana Maria. European Portuguese and Brazilian Portuguese: an Overview on Word order. In: WETZELS, Leo; Menuzzi Sérgio; COSTA, João (eds.) The Handbook of Portuguese Linguistics. Wiley, Blackwell. 2016: $15-40$.

ORDOÑEZ, Francisco. Topic-subjects in Brazilian Portuguese and clitic left dislocation in Dominican Spanish. SYNTAX, 22 (2-3), 229-247, 2019.

KAYNE, Richard. Microparametric syntax: Some introductory remarks. In: BLACK, James; Montapaniane, V. (eds) Microparametric Syntax and Dialect Variation. Amsterdam: John Benjamins, 1996: IX-XVIII.

$\mathrm{KROCH}$, Anthony. Morphosyntactic variation. In: Beals, K et al. (eds.) Papers from the 30th Regional Meeting of the Chicago Linguistic Society. Parassession on Variation \& Linguistic Theory. 1994, Vol. II: 180-201.

KURODA, Sige-Yuki. The categorical and the thetic judgements. Foundations of Language, 9. 153-185, 1972.

LIGHTFOOT, David. How to set parametera: arguments from language change. Cambridge, MA: MIT Press, 1991.

The Development of Language: Acquisition, Change and Evolution. Cambridge, MA: The MIT Press, 1999. 
MAGALHÃES, Telma. Aprendendo o Sujeito Nulo na Escola. Dissertação de Mestrado. Campinas, UNICAMP, 2000.

MODESTO, M. Topic prominence and null subjects. In: BIBERAUER Teresa (ed.) The limits of syntactic variation. Amsterdam: Benjamins, 2008: 375-410.

NEGRÃO, Esmeralda V. Português brasileiro: uma língua voltada para o discurso. São Paulo, 1999. Tese de Livre Docência - FFLCH, Universidade de São Paulo, 1999.

NUNES, Jairo. Direção de cliticização, objeto nulo e pronome tônico na posição de objeto no português brasileiro. In: ROBERTS, Ian; KATO, Mary A. (eds.). 1993: 161-174. $3^{a}$ ed. São Paulo: Editora Contexto, 2018: 161-173.

Clíticos acusativos de terceira pessoa em português brasileiro como concordância de objeto. In: GALVES, Charlotte; KATO, Mary A; ROBERTS.], Ian (orgs.) Português Brasileiro: uma segunda viagem diacrônica. Campinas: Editora da Unicamp, 2019: 151-172.

PAGOTTO, Emílio. G. Clíticos, mudança e seleção natural. In: ROBERTS, lan; KATO, Mary A. (eds.). 1993: 143-160. $3^{\text {a }}$ ed. São Paulo: Editora Contexto, 2018: 143-160.

PERLMUTTER, David. Deep and Surface Constraints in Syntax. New York: Holt, Rhinehart and Winston, 1971.

PILATI, Eloisa. (2006) Aspectos Sintáticos e Semânticos da ordem verbo-sujeito no Português. Tese de Doutorado, Universidade de Brasília. 2006

PONTES, Eunice. (1981) Da importância do tópico em português. Comunicação no V Encontro Nacional de Linguística. PUC-RJ. Publicado em seus Anais. v. 2.

O Tópico no Português do Brasil. Campinas: Pontes Eds. 1987.

ROBERTS, Ian. A deletion analysis of null subjects. In: BIBERAUER, Teresa; HOLMBERG, Anders; ROBERTS, Ian; SHEEHAN, Michelle (eds.) 2010: 58-87.

\& HOLMBERG, Anders. Introduction: parameters in Minimalist theory. In: BIBERAUER, Teresa; HOLMBERG, Anders; ROBERTS, lan; SHEEHAN, Michelle (eds.) 2010, 1-57.

; KATO, Mary A. Português Brasileiro: uma viagem diacrônica. Campinas, Editora da UNICAMP, 1993. São Paulo: Editora Contexto 3ª . Edição, 2018.

SIMÕES, Luciene. J. Null subjects in Brazilian Portuguese: developmental data from a case study. In: KATO, Mary A.; NEGRÃO, Esmeralda V. (eds.), 2000:75-104.

ZUBIZARRETTA, Maria Luísa. Prosody, Focus and Word Order. Linguistic Inquiry Monographs, 33, 1988, The MIT Press. 